\title{
Role of Multi Detector Computed Tomography in Evaluation of Vascular Complications of Pancreatitis: A Cross-sectional Study
}

\begin{abstract}
Introduction: The involvement of the blood vessels around the pancreas in pancreatitis may result in devastating complications. The proteolytic enzymes secreted by the inflamed pancreas can directly erode the walls of arteries in and around the pancreas, resulting in haemorrhage or pseudoaneurysms formation. On the other hand, the inflamed tissue may compress or thrombose adjoining veins. Multidetector Computed Tomography (MDCT) serves as an excellent tool for diagnosis and evaluation of complications of pancreatitis and can detect most vascular complications.
\end{abstract}

Aim: To evaluate the MDCT findings of vascular complications associated with pancreatitis.

Materials and Methods: This cross-sectional study was conducted on 60 patients at the Department of Radiology in the Tertiary Care Hospital attached to Mysore Medical College and Research Institute, Mysore, India for 12 months from $1^{\text {st }}$ August 2019 to $31^{\text {st }}$ July 2020 . Each patient was subjected to unenhanced and contrast-enhanced CT to characterise the vascular complications associated with pancreatitis. The results were tabulated and evaluated descriptively by Microsoft excel 2016 and presented in figures and tables.

Results: Of the 60 patients included, Splenic Vein Thrombosis (SVT) was seen in 39 (65\%), followed by Portal Vein (PV) thrombosis in $17(28.3 \%)$, Superior Mesenteric Vein (SMV) thrombosis in $14(23.3 \%)$, all the three vein thrombosis was seen in $7(11.6 \%)$ and arterial pseudoaneurysms was seen in $3(5 \%)$.

Conclusion: Vascular complications in pancreatitis are not uncommon but should be evaluated in all cases of pancreatitis. Contrast-enhanced CT is the main imaging modality for originally identifying local complications. SVT is one of the most frequently found vascular complications seen in patients of pancreatitis.

Keywords: Complications, Computed tomography scan, Pseudoaneurysms, Venous thrombosis

\section{INTRODUCTION}

Acute pancreatitis is a common disease in the developing world that is characterised by a diffuse inflammatory process affecting the pancreas and triggered by the leakage and extravasation of activated pancreatic secretions. Acute pancreatitis leads to a wide range of local and systemic pathophysiologic alterations and large variability in the clinical manifestation and prognosis [1]. Chronic pancreatitis is an irreversible inflammatory disease of the pancreas converting to fibrosis. Intermittently, chronic pancreatitis may give rise to inflammatory pseudo mass thus, producing focal enlargement with fibrosis [2]. Local complications may cause a very serious clinical problem, i.e., bleeding from the blood vessels damaged by inflammation into pathologic fluid cisterns, the retroperitoneal area, or the peritoneal cavity. Although pancreatitis associated vascular complications are rare, they can lead to death in a very short time. They occur both, in acute and chronic pancreatitis. Vascular complications of pancreatitis are more common in chronic pancreatitis (7-10\%) than in acute pancreatitis with frequency of 1.2$14.5 \%$ [3]. The mortality rate in acute pancreatitis due to haemorrhage has been reported in 34-52\% and is higher than in cases of patients without haemorrhagic complications. Major vascular complications in pancreatitis are not common and all have to be evaluated for vascular complications to avoid potentially devastating adverse effects. The most dreadful complication of all is rupture of arterial pseudoaneurysm [3]. MDCT imaging plays an important role in the diagnosis of these vascular complications [4]. Since, major vascular complications of pancreatitis are life threatening, early diagnosis of these can be lifesaving in patients. Many a times these complications go unidentified due to lack of proper investigations. The excellent visualisation of the parenchymal pathologies by MDCT and the ability to evaluate extrapancreatic complications in inflammatory conditions makes MDCT the modality of choice to diagnose acute and chronic pancreatitis and its vascular complications. Thus, MDCT helps to diagnose and describe the findings of vascular complications associated with pancreatitis. With this background, the present study was conducted with an aim to describe the MDCT findings of vascular complications associated with pancreatitis.

\section{MATERIALS AND METHODS}

This cross-sectional study was done at the Department of Radiology in Krishna Rajendra Tertiary Care Hospital attached to Mysore Medical College and Research Institute, Mysore, India for 12 months from $1^{\text {st }}$ August 2019 to $31^{\text {st }}$ July 2020. Institutional Ethical Committe approval was obtained (EC REG: ECR/134/Inst/ KA/2013/RR-19). The series consists of patients with pancreatitis which were diagnosed using clinical details like upper abdominal pain, vomiting, epigastric tenderness along with raised serum amylase, and lipase, which were sent directly for CT examination as well as the patients in whom abdominal ultrasound examination was suggestive of pancreatitis [5]. Axial CT examination was carried out in supine position, both unenhanced and enhanced study was done with intravenous iodinated contrast agents, namely lopromide (Ultravist) or lohexol (Omnipaque). After assessing pancreatitis and its local complications, a thorough examination of blood vessels adjacent to the pancreas was made for mass effect, thrombosis, and abnormal dilatation.

Inclusion criteria: After thorough examination, patients who had vascular complications like thrombus in splenic vein, PV, SMV, and arterial pseudoaneurysms were included in the study. 
Exclusion criteria: The patients who had history of allergy to iodinated contrast agents, deranged renal, function tests, pregnant women, patients with unstable general conditions, and postoperative cases were excluded from the study.

Based on the inclusion and exclusion criteria, a total of 60 patients were included in the study after obtaining the informed written consent by the patients. Computed Tomography of the abdomen and pelvis was performed with 128 slice single-source dual-energy SOMATOM Definition Edge Siemens MDCT (Multidetector CT) machine. Pre-procedure preparation included that the patients should be nil per oral for about six hours before conducting the study with normal renal function tests. Initially, the unenhanced study was done followed by an intravenous contrast study, and the iodinated contrast agents namely lopromide (Ultravist) or lohexol (Omnipaque) were used at $2 \mathrm{~mL} / \mathrm{kg}$ body weight. Scans were obtained in the portal phase. Arterial and delayed scans were also obtained whenever necessary.

The region from both domes of the diaphragm to pubic symphysis was included. The patients' position was supine with arms above the head and the following parameters were used: $300 \mathrm{~mA}, 100 \mathrm{kV}$, pitch $0.8,0.5 \mathrm{~s}$ tube rotation time, slice thickness $5 \mathrm{~mm}$, scan orientation: craniocaudal, scan delay: $45 \mathrm{~s}$ and FOV: $350 \mathrm{~mm}$. The images were reconstructed to obtain $1 \mathrm{~mm}$ section in sagittal and coronal planes.

\section{STATISTICAL ANALYSIS}

The results of the study were tabulated and evaluated descriptively by Microsoft Excel 2016. Also, the results were presented in figures and tables.

\section{RESULTS}

In this study, 60 patients of pancreatitis in whom vascular complications were detected on MDCT were analysed. The patient's age ranged from 2 to 68 years. The most commonly affected age group was the $2^{\text {nd }}$ to $3^{\text {rd }}$ decade (43.33\%), the least affected group was less than the 20 year age group [Table/Fig-1]. The study group included 51 males (85\%) and 9 females (15\%) with male preponderance. SVT was seen in $39(65 \%)$, PV thrombosis in $17(28.3 \%)$, SMV thrombosis in 14 (23.3\%), all the three-vein

\begin{tabular}{|l|c|c|}
\hline Age (years) & Number & Percentage (\%) \\
\hline $0-20$ & 6 & 10 \\
\hline $21-40$ & 26 & 43.33 \\
\hline $41-60$ & 20 & 33.33 \\
\hline$>60$ & 8 & 13.33 \\
\hline Total & 60 & 100 \\
\hline
\end{tabular}

\begin{tabular}{|l|l|c|c|}
\hline $\begin{array}{l}\text { Vascular } \\
\text { complications }\end{array}$ & \multicolumn{1}{|c|}{ Complication findings } & $\begin{array}{c}\text { Number } \\
\text { of cases }\end{array}$ & $\begin{array}{c}\text { Percentage } \\
(\%)\end{array}$ \\
\hline \multirow{4}{*}{$\begin{array}{l}\text { Arterial } \\
\text { complications }\end{array}$} & Pseudoaneurysms & 3 & 5 \\
\cline { 2 - 4 } & Splenic artery Pseudoaneurysms & 2 & 3.3 \\
\cline { 2 - 4 } & $\begin{array}{l}\text { Gastroduodenal artery } \\
\text { Pseudoaneurysms }\end{array}$ & 1 & 1.6 \\
\hline \multirow{4}{*}{$\begin{array}{l}\text { Venous } \\
\text { complications }\end{array}$} & Splenic vein thrombosis & 39 & 65 \\
\cline { 2 - 4 } & Portal vein thrombosis & 17 & 28.3 \\
\cline { 2 - 4 } & Superior mesenteric vein thrombosis & 14 & 23.3 \\
\cline { 2 - 4 } & Splenic vein + portal vein thrombosis & 1 & 1.6 \\
\cline { 2 - 4 } & Splenic vein + SMV thrombosis & 2 & 3.3 \\
\cline { 2 - 4 } & Portal vein and SMV thrombosis & 1 & 1.6 \\
\cline { 2 - 4 } & $\begin{array}{l}\text { Splenic vein + portal vein + SMV } \\
\text { thrombosis }\end{array}$ & 7 & 11.6 \\
\hline
\end{tabular}

thrombosis was seen in 7 (11.6) [Table/Fig-2]. SVT was the most common vascular complication seen in the present study, seen as contrast non-opacification of splenic vein [Table/Fig-3], followed by $\mathrm{PV}$ thrombosis which can involve main $\mathrm{PV}$ or branches of PV or entire length of its course [Table/Fig-4] and the least commonly affected vein among three was SMV, which commonly seen as nonopacification at its confluence with splenic vein, also complete nonopacification of SMV and its tributaries can be seen [Table/Fig-5]. Pseudoaneurysm seen as contrast outpouching from the arteries [Table/Fig-6,7].
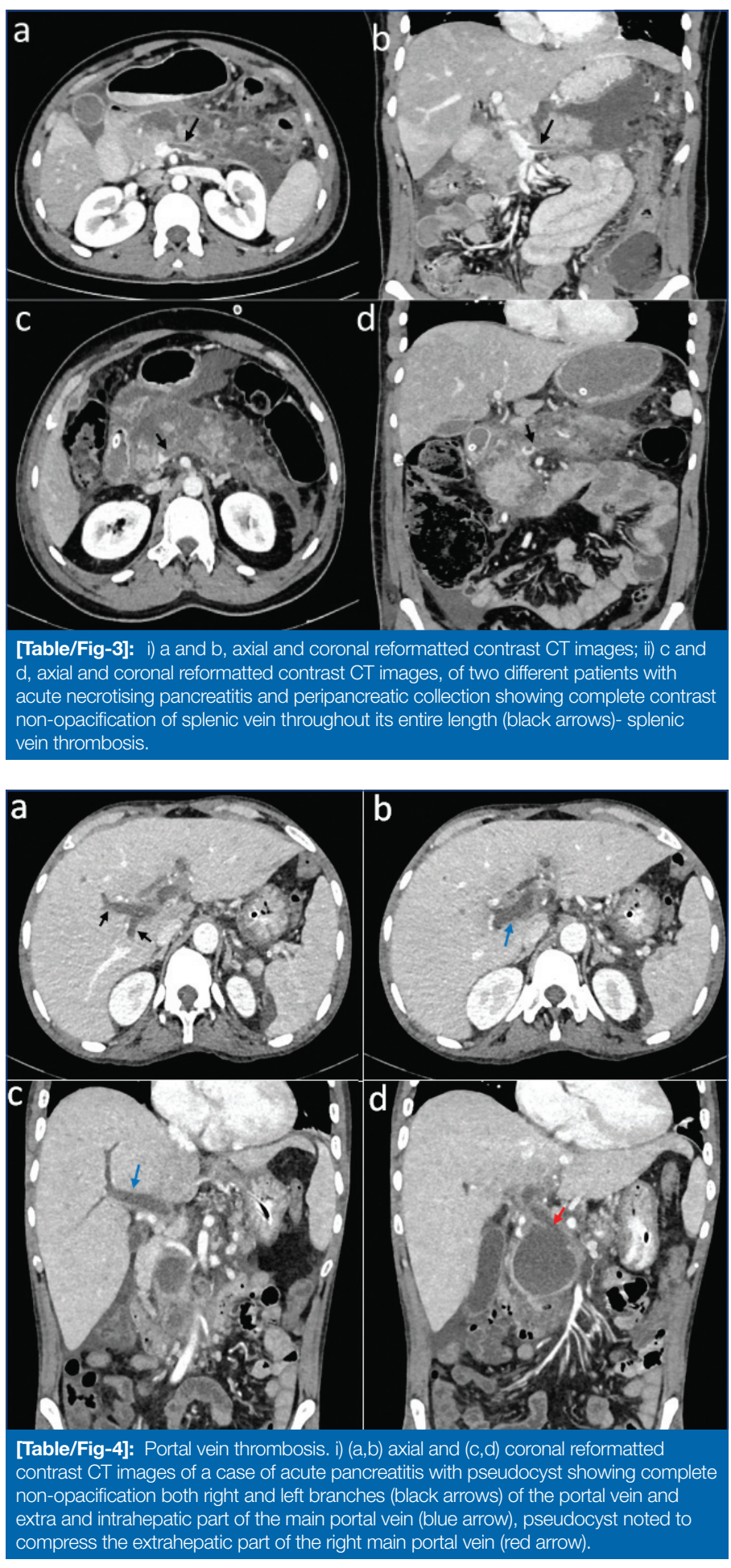

\section{DISCUSSION}

In the present study, consisting of 60 cases of pancreatitis, vascular complications were most commonly seen in $2^{\text {nd }}$ to $3^{\text {rd }}$ decade (43.33\%) with male predominance (85\%), SVT was seen in 39 cases (65\%) and was the commonest vascular complication, followed by PV thrombosis in 17 patients (28.3\%), SMV thrombosis in 14 patients (23.3\%), and arterial pseudoaneurysms was seen in 3 patients (5\%). 



Two cases of splenic artery pseudoaneurysm and one case of GDA pseudoaneurysm were seen. The results of this study were similar to a study conducted by Sanjay D and Magdum A, which showed SVT in 11 cases $(64.7 \%)$ out of 17 cases of pancreatitis with vascular complications and PV thrombosis was seen 2 cases out of 17 cases of pancreatitis with vascular complications out of 47 patients of pancreatitis that were studied [6]. The present study results were also similar to the studies conducted by Mallick $\mathrm{IH}$ and Winslet MC, Bernades $P$ et al., and Boudghene F et al [7-9].

Vascular complications are seen in approximately $25 \%$ of patients with pancreatitis, with complications ranging from SVT, pseudoaneurysm formation and rupture, haemorrhage into pseudocyst, erosions of the upper Gastrointestinal (Gl) arteries, and variceal formation [10-12]. The risk factors include necrotising pancreatitis, multi-organ failure, sepsis, and pancreatic fluidcollections such as abscesses, pseudocysts, or walled-off necrosis [13].

Severe pancreatic inflammation and necrosis is one of the major causes of vessel injury, which leads to the local spread of exocrine proteolytic and lipolytic enzyme-rich fluids. These fluids cause erosion of the vessel wall, which may result in pseudoaneurysm formation (when there is bleeding into a contained space or organ), haematoma (when pseudoaneurysm is thrombosed or there is no active extravasation), or frank intraperitoneal haemorrhage (when there is rupture of pseudoaneurysm) [13].

The pancreas is closely related to the splenic vein, inferior mesenteric vein, SMV, and PV. Local inflammation by peripancreatic fluidcollection or compression by pseudocysts results in SVT which may result in isolated left-sided portal hypertension, gastroesophageal variceal formation and eventual Gl bleeding. Hence, SVT is likely to occur in the presence of pseudocysts and severe necrotising pancreatitis [13]. Complications linked with PV involvement are mostly due to thrombosis; PV rupture and development of pancreaticoportal fistulas are very rare with few cases being reported [14].

The most common complications are thrombosis of the portal venous system [7]. Isolated SVT occurring in about approximately 10-40\% of cases is more common in patients with chronic pancreatitis [10]. Portal and SMV thrombosis also occur as a result of pancreatitis, even though less common than SVT [15]. Diagnosis of SVT may be difficult as many cases are asymptomatic. MDCT is very useful in the diagnosis of SVT. The observations on CT scan are: extensive, irregular, dilated enhancing vascular channels around the splenic vein (i.e., short gastric veins in the gastrosplenic ligament, dilated gastroepiploic or coronary vein) or a vein with filling defect resulting in partial contrast opacification [16]. Recognition of an enlarged left gastroepiploic vein, without a recanalised umbilical vein, strongly suggests a diagnosis of SVT and not a result of portal hypertension and is hence useful for differentiating between these two vascular complications; this distinction is cardinal since their treatment differs totally [17].

A pseudoaneurysm has been reported to happen in $3.5-10 \%$ of patients with pancreatitis [18]. The involved arteries include, in order of frequency, the splenic artery was most common (40\%) followed by gastroduodenal (30\%), pancreaticoduodenal (20\%), gastric $(5 \%)$, hepatic $(2 \%)$, and other less commonly involved namely superior mesenteric, jejunal, ileocaecal, aorta which constituted for $1-3 \%[9,19-23]$. The rupture of a pseudoaneurysm is a deadly complication of pancreatitis. The pseudoaneurysm can rupture into the pseudocyst/Gl tract/peritoneal cavity or pancreatic parenchyma $[24,25]$. Pseudoaneurysms may rupture rarely into the pancreatic duct called "Haemosuccus pancreatitis" and the bleeding from the ampulla of Vater is seen on endoscopic examination [26,27]. "Pseudoaneurysmaticpseudocyst" is referred to as a condition if the 
visceral artery is involved in the wall of pseudocyst [28]. A rare case was reported by Suzuki $T$ et al., in which GDA pseudoaneurysm had ruptured into the SMV [29]. The size of the pseudoaneurysm is not a determinant of rupture [30]. Pseudoaneurysms are a rare but serious complication of pancreatitis with the potential for rupture and life-threatening haemorrhage which, if undetected, results in high mortality. The best initial management is Endovascular Embolisation (EE) and if that fails it should be followed by emergency surgery without delay $[31,32]$.

Although angiography is considered the gold standard, the initial imaging of these patients is usually helical Computerised Tomography (CT) scan, as angiography is not always available. The CT scan finding of contrast enhancement within or adjacent to a suspected pseudocyst is suspicious of a pseudoaneurysm. The enhancement may be similar to that of the abdominal aorta. The finding of increased attenuation within a fluid collection on a non-enhanced scan may indicate a recent haemorrhage. MDCT plays a significant role in the diagnosis of detecting these vascular complications of pancreatitis [33]. Also, MDCT helps in determining the cause of pancreatitis [34].

According to Cesare ED et.al., documentation of the incidence of vascular thrombosis has increased over time due to considerable developments in cross-sectional imaging modalities [35]. The true evaluation and prediction of the risk of haemorrhage due to pancreatitis induced thrombosis of the splenic vein have been commonly confounded by failure to exclude pancreatic malignancies and extrapancreatic causes of the thrombosis. In their study, which was based on a computerised index search from 1992-2003, of the 53 patients who were diagnosed with pancreatitis and presence of SVT, 13 patients had acute pancreatitis [36].

In a more recent study, on 127 patients over two years by Gonzelez HJ et al., 20 patients were seen to have SVT. They proposed that venous thrombosis in patients of pancreatitis is a common observation and that overlap of peripancreatic collections and SVT strongly advocated the mechanism to be compression and perivascular inflammation [37].

\section{Limitation(s)}

This study was not aimed at deriving the intervention and management of the condition, nor was there any follow-up to establish the sequelae of these complications. However, significant findings were identified. Also, as the study was conducted in a single institute, it was limited to a less myriad group of patients.

\section{CONCLUSION(S)}

Vascular complications following pancreatitis are not uncommon and should be evaluated in each and every case of pancreatitis. Diagnosing and managing these complications will result in a remarkable reduction of morbidity and mortality. SVT is one of the most frequently found vascular complications seen in patients of pancreatitis. Timely diagnosis and management will be useful to lower morbidity and mortality. A multicentre study would be even more meticulous in studying the prevalence of vascular complications in patients with pancreatitis.

\section{REFERENCES}

[1] Lenhart DK, Balthazar EJ. MDCT of acute mild (non-necrotising) pancreatitis: Abdominal complications and fate of fluid collections. AJR Am J Roentgenol. 2008;190(3):643-49

[2] Balthazar EJ. Acute pancreatitis: Assessment of severity with clinical and CT Evaluation. Radiology. 2002;223(3):603-13.

[3] Sharma PK, Madan K, Garg PK. Hemorrhage in acute pancreatitis: should gastrointestinal bleeding be considered an organ failure? Pancreas. 2008;36(2):141-45.
[4] Masud R, Waheed A, Aurangzeb, Malik FI, Mian A. Role of radiology in pancreatic disorders, Pak. Armed Forces Med J. 2009;59(1):103-08.

[5] Quinlan JD. Acute pancreatitis. Am Fam Physician. 2014;90(9):632-39.

[6] Sanjay D, Magdum A. MDCT evaluation of acute pancreatitis. JMSCR 2017;05(08):26894-97.

[7] Mallick $\mathrm{H}$, Winslet MC. Vascular complications of pancreatitis. JOP. 2004;5:328-37.

[8] Bernades P, Baetz A, Levy P, Belghiti J, Menu Y, Fekete F. Splenic and portal venous obstruction in chronic pancreatitis. A prospective longitudinal study of a medical-surgical series of 266 patients. Dig Dis Sci. 1992;37(3):340-46.

[9] Boudghene F, L'Hermine C, Bigot JM. Arterial complications of pancreatitis: Diagnostic and therapeutic aspects in 104 cases. J Vasc Interv Radiol. 1993;4:551-58. doi: 10.1007/BF01307725.

[10] De Rosa A, Gomez D, Pollock JG, Bungay P, De Nunzio M, Hall RI, et al. The radiological management of pseudoaneurysms complicating pancreatitis. JOP. 2012;13(6):660-66.

[11] Vogelzang RL, Gore RM, Anschuetz SL, Blei AT. Thrombosis of the splanchnic veins: CT diagnosis. AJR Am J Roentgenol. 1988;150(1):93-96.

[12] Hourani S Al, Al-Bdour MN, Rashaideh MA, Al-Nawayseh KR, Alasmar AA, Alkasasbeh MA, et al. Pseudo aneurysm complicates pancreaticpseudo cyst: Importance of early detection and management. J Surg Pak (International). 2008;13: PD09-10: doi: 10.7860/JCDR/2017/25314.9651.

[13] Flati G, Andrén-Sandberg A, La Pinta M, Porowska B, Carboni M. Potentially fatal bleeding in acute pancreatitis: Pathophysiology, prevention, and treatment. Pancreas. 2003;26(1):08-14.

[14] Charvat F, Maskova J, Belina F, Buric I, Lacman J, Fuksa Z, et al. Portal vein erosion: A rare hemorrhagic complication of acute pancreatitis treated by percutaneous stent-graft placement. J Vasclnterv Radiol. 2010;21(3):411-12.

[15] Rattner DW, Warshaw AL. Venous, biliary, and duodenal obstruction in chronic pancreatitis. Hepatogastroenterology. 1990;37(3):301-06.

[16] Belli AM, Jennings CM, Nakielny RA. Splenic and portal venous thrombosis: A vascular complication of pancreatic disease demonstrated on computed tomography. Clin Radiol. 1990;41(1):13-16.

[17] Marn CS, Edgar KA, Francis IR. CT diagnosis of splenic vein occlusion: Imaging features, etiology and clinical manifestations. Abdom Imaging. 1995;20:78-81. [PMID 7894307].

[18] White AF, Baum S, Buranasiri S. Aneurysms secondary to pancreatitis. AJR Am J Roentgenol. 1976;127(3):393-96.

[19] Woods MS, Traverso LW, Kozarek RA, Brandabur J, Hauptmann E. Successful treatment of bleeding pseudoaneurysms of chronic pancreatitis. Pancreas. 1995;10:22-30. [PMID 7899456].

[20] Suzuki T, Ishida H, Komatsuda T, Oyake J, Miyauchi T, Heianna J, et al. Pseudoaneurysm of the gastroduodenal artery ruptured into the superior mesenteric vein in a patient with chronic pancreatitis. J Clin Ultrasound. 2003;31:278-82. [PMID 12767023].

[21] Toscano RL, Ruiz OR, Gerace CA Jr. Rupture of splenic artery pseudoaneurysm. Am Surg. 1995;61:940-42. [PMID 7486420].

[22] Yeh TS, Jan YY, Jeng LB, Hwang TL, Wang CS, Chen MF. Massive extraenteric gastrointestinal hemorrhage secondary to splanchnic artery aneurysms. Hepatogastroenterology. 1997;44:1152-56. [PMID 9261616].

[23] Giles RA, Pevec WC. Aortic pseudoaneurysm secondary to pancreatitis. J Vasc Surg. 2000;31:1056-59. [PMID 10805901].

[24] Dinu F, Deviere J, Van Gossum A, Golzarian J, Dussaussois L, Delhaye M, et al. The wirsungorrhagies: Causes and management in 14 patients. Endoscopy. 1998;30:595-600. [PMID 9826136].

[25] Kuganeswaran E, Smith OJ, Goldman ML, Clarkston WK. Hemosuccuspancreaticus: Rare complication of chronic pancreatitis. Gastrointest Endosc. 2000;51:464-65. [PMID 10744821].

[26] Wagner WH, Cossman DV, Treiman RL, Foran RF, Levin PM, Cohen JL. Hemosuccuspancreaticus from intraductal rupture of a primary splenic artery aneurysm. J Vasc Surg. 1994;19:158-64.

[27] IgariK, OchiaiT, AiharaA, KumagaiY, lidaM, YamazakiS. Hemosuccuspancreaticus caused by a primary splenic artery aneurysm as a rare cause of gastrointestinal bleeding: Report of a case. Int Surg. 2010;5:325-28.

[28] Masatsugu T, Yamaguchi K, Yokohata K, Mizumoto K, Chijiiwa K, Tanaka M. Hemorrhagicpseudocyst and pseudocyst with pseudoaneurysm successfully treated by pancreatectomy: Report of three cases. J Hepatobiliary Pancreat Surg. 2000;7(4):432-37.

[29] Suzuki T, Ishida H, Komatsuda T, Oyake J, Miyauchi T, Heianna J, et al. Pseudoaneurysm of the gastroduodenal artery ruptured into the superior mesenteric vein in a patient with chronic pancreatitis. J Clin Ultrasound. 2003;31:278-82. [PMID 12767023].

[30] Tessier DJ, Stone WM, Fowl RJ, Abbas MA, Andrews JC, Bower TC, et al. Clinical features and management of splenic artery pseudoaneurysm: Case series and cumulative review of literature. J Vasc Surg. 2003;38:969-74. [PMID 14603202].

[31] De Rosa A, Gomez D, Pollock JG, Bungay P, De Nunzio M, Hall Rl, et al. The radiological management of pseudoaneurysms complicating pancreatitis. JOP. 2012;13(6):660-66.

[32] Varshney P, Songra B, Mathur S, Gothwal S, Malik P, Rathi M, et al. Splenic artery pseudoaneurysm presenting as massive hematemesis: A diagnostic dilemma case. Case Rep Surg. 2014;2014:501937.

[33] Balthazar EJ, Fisher LA. Hemorrhagic complications of pancreatitis: Radiologic evaluation with emphasis on CT imaging. Pancreatology. 2001;1:306-13. [PMID 12120209] 
[34] Chandna P, Yadav RK. Importance of MDCT in Evaluation of Pancreatitis. IOSR Journal of Dental and Medical Sciences. (IOSR-JDMS). 2019;18(4):74-83.

[35] Di Cesare E, Di Sibio A, Gennarelli A, Felli V, Vellucci V, Casazza I, et al. An unusual case of ascending pancreatitis with mediastinal involvement: A case report with CT and MRI findings. Case Rep Radiol. 2014;2014:925105.
[36] Heider TR, Azeem S, Galanko JA, Behrns KE. The natural history of pancreatitisinduced splenic vein thrombosis. Ann Surg. 2004;239(6):876-72.

[37] Gonzelez HJ, Sahay SJ, Samadi B, Davidson BR, Rahman SH. Splanchnic vein thrombosis in severe acute pancreatitis: A 2-year, single-institution experience. HPB (Oxford). 2011;13:860-64

\section{PARTICULARS OF CONTRIBUTORS:}

1. Associate Professor, Department of Radiology, Mysore Medical College and Research Institute, Mysore, Karnataka, India

2. Professor, Department of Radiology, Mysore Medical College and Research Institute, Mysore, Karnataka, India

3. Senior Resident, Department of Radiology, Mysore Medical College and Research Institute, Mysore, Karnataka, India.

4. Resident, Department of Radiology, Mysore Medical College and Research Institute, Mysore, Karnataka, India.

5. Resident, Department of Radiology, Mysore Medical College and Research Institute, Mysore, Karnataka, India.

6. Resident, Department of Radiology, Mysore Medical College and Research Institute, Mysore, Karnataka, India.

7. Resident, Department of Radiology, Mysore Medical College and Research Institute, Mysore, Karnataka, India.

8. Resident, Department of Radiology, Mysore Medical College and Research Institute, Mysore, Karnataka, India.

\section{NAME, ADDRESS, E-MAIL ID OF THE CORRESPONDING AUTHOR:}

Dr. Tilaka,

Room No. 201, PG Hostel for Men, MMCRI, Irwin Road,

Mysore-570001 Karnataka, India.

E-mail: tilakatlk@gmail.com

\section{PLAGIARISM CHECKING METHODS: [Jain Het al.]}

- Plagiarism X-checker: Oct 01, 2020

- Manual Googling: Dec 07, 2020

- iThenticate Software: Jan 12, 2021 (20\%)
ETYMOLOGY: Author Origin

\section{AUTHOR DECLARATION:}

- Financial or Other Competing Interests: None

- Was Ethics Committee Approval obtained for this study? Yes

- Was informed consent obtained from the subjects involved in the study? Yes

- For any images presented appropriate consent has been obtained from the subjects. Yes
Date of Submission: Sep 30, 2020

Date of Peer Review: Nov 19, 2020

Date of Acceptance: Dec 28, 2020

Date of Publishing: Apr 01, 2021 